\title{
Aging and oral health
}

\section{Opinion}

The mouth reflects a person's health and well being throughout the life. Oral diseases can have an impact on many aspects of general health and health conditions can in turn have an impact on oral health. ${ }^{1}$ The aging process can be as hard on our mouths, teeth and gums as it is onother parts of our bodies. As we get older, we are more susceptible to thebuildup of plaque and the weakening and cracking of older fillings. In addition, there is a tendency for our teeth to become brittle, and many seniors suffer fromdiminished muscular control, which can make chewing or wearing dentures moredifficult. Finally, the older we get, the more vigilant we need to be againstdeveloping gum disease. Based on a recent study the risk of malnutrition tripled when mouth is unhealthy. ${ }^{2}$ Compared to previous decades, the elderly population today is much more predominant in the world and continues to rapidly increase due to longer life expectancy and the effects of the baby boom generation. ${ }^{3}$

\section{Oral health related quality of life}

This term is often used to describe the impact that one's oral health can have on their daily life experiences, it reflects the reality that modern dentistry is not just aiming to prolong life or eliminate oral disease, but ultimately is attempting to make life better. ${ }^{1,2}$ Most of the changes in oral health of elderly are the consequences of chronic disease and medications accompanied by physical disability; it is proved that a link between poor oral health and other diseases exist. Few diseases and their association with poor oral health are described here. ${ }^{4}$

\section{Pneumonia}

Bacterial pneumonia is a leading cause of death in elderly individuals. The microorganisms that cause pneumonia are commonly found in significantly high concentrations in the dental plaque of people with gum disease. Many studies havedemonstrated that poor oral hygiene in older adults is a major risk factor forpneumonia, in particular a strain called "aspiration pneumonia", which is causedby bacteria-laden saliva accidentally entering the windpipe and travelling to the lungs. ${ }^{5}$

\section{Diseases}

Several studies have shown that having gum disease increases one's risk of developing cardiovascular disease (CVD) [1]. Inflammation is a major risk factor for heart disease, and the bacterial accumulations associated with periodontal disease can increase inflammation levels throughout the entire body. ${ }^{3-6}$

\section{Diabetes}

Diabetics are particularly susceptible to contracting infections; they are at greater risk than most people of developing gum disease. At the same time, oral infections can increase the severity of diabetes by increasing blood sugar levels, leading to such complications as premature degeneration of the eyes, kidneys, nerves and blood vessels. $^{7}$
Volume 6 Issue 3 - 2017

\author{
Nilesh Pardhe, Manas Bajpai \\ Department of Oral Pathology \& Microbiology, NIMS Dental \\ College, India
}

Correspondence: Nilesh Pardhe, Department of Oral Pathology \& Microbiology, NIMS Dental College, Jaipur, India, Email drpardhenilesh@hotmail.com

Received: February 02, 2016 | Published: February 08, 2016

\section{Malnutrition}

There is a clear relationship between poor oral health and malnutrition in the elderly. Older individuals with good oral health benefit from being able to eat a much broader variety of nutritious foods than those with pain, discomfort or tooth loss. ${ }^{6}$ The researchers concluded that poor dental health, combined with diminished ability to communicate, can cause weight loss, dehydration and infirmity. ${ }^{8}$ In addition to helping prevent the conditions listed above, good oral health and hygiene have been associated in less direct ways with the prevention of other diseasesi.e osteoporosis and rheumatoid arthiritis in different ways. ${ }^{5}$

\section{Osteoporosis}

The disease is characterized by decreased bone density and weakened bones. As it progresses, osteoporosis can compromise bones to the point that they break under otherwise normal stresses. It is often considered a "silent disease" that has few symptoms in its early stages. ${ }^{2}$ There is a strong relationship between bone metabolism and oral health, anddentists are in a unique position to help identify people with low bone density. Early signs of osteoporosis can often be seen in the mouth and detected throughoral examination and dental X-rays. ${ }^{8}$

\section{Rheumatoid arthiritis}

There is also evidence that treating severe gum disease may alleviate some ofthe symptoms of rheumatoid arthritis (RA) in people suffering from bothconditions. RA and periodontitis are both common chronic inflammatoryconditions. Researchers have concluded that non-surgical periodontal therapyhad a beneficial effect on the signs and symptoms of RA, regardless of themedications being used to treat the condition. ${ }^{2-8}$ Good oral health is essential to healthy aging. Because effectiveinterventions to prevent and control oral disease exist, good oralhealth can be achieved by older adults. The public health systemcan play a vital role in ensuring that this occurs.

\section{Funding}

None. 


\section{Acknowledgments}

None.

\section{Conflicts of interest}

The authors declare that there is no conflict of interest.

\section{References}

1. Rosenoer LM, Sheiham A. Dental impacts on daily life and satisfaction with teeth in relation to dental status in adults. J Oral Rehabil. $1995 ; 22(7): 469-480$.

2. Burt BA, Eklund SA. Dentistry, dental practice, and the community. Elsevier Saunders, St. Louis, Missouri: USA; 2005. 224 p.

3. Jones G, Cooley HM. Symptomatic fracture incidence in those under 50 years of age in southern Tasmania. Journal of Paediatrics and Child Health. 2002;38(3):278-283.
4. Eli I, Bar Tal Y, Kostovetzki I. At first glance: social meanings of dental appearance. J Public Health Dent. 2001;61(3):150--154.

5. Strayer MS. Dental health among homebound elderly. J Public Health Dent. 1993;53(1):12-16.

6. Mock C, Cherian MN. The global burden of musculoskeletal injuries: challenges and solutions. Clin Orthop and Relat Res. 2008;466(10):23062316.

7. Heitz Mayfield LJ, Trombelli L, Heitz F, et al. A systematic review of the effect of surgical debridement vs non-surgical debridement for the treatment of chronic periodontitis. J Clin Periodontol. 2002;29(Suppl 3):92-102.

8. Polinder S, Meerding WJ, Mulder S, et al. Assessing the burden of injury in six European countries. Bull World Health Organ. 2007;85(1):27-34. 